\title{
MEMBANGUN KARAKTER GENERASI PENERUS MELALUI PASRAMAN
}

\author{
Oleh: \\ Ni Wayan Karmini \\ Pascasarjana Universitas Hindu Indonesia, Denpasar \\ karmini.niwayan@yahoo.com
}

\begin{abstract}
Among the destructive social phenomena coloring the current era of globalization, is the strengthening of the ideology of Individualism, the decline of morality, and the culture of consumerism that tends to be unfavorable for the future of future generations. These problems can be anticipated through pasraman hearing. This paper will discuss (1) why pasraman is needed in building the character of personality of the young generation of Bali? (2) how the pasraman can be effective in building the character of personality of the young generation of Bali. This paper is the result of a descriptive evaluative study whose data were obtained from documentation studies and interviews with 12 participant informants and the organization of Pasraman Yuana Bhuana Giri, at Perumnas Bukit Sanggulan, Tabanan. The results of the study prove that first, pasraman is needed to form the character and personality of the next generation who have good character (good morality), not stuck into the culture of consumerism, have a hard work ethic, and have the motivation to move forward, ready to compete with advanced nations others. Second, the arrangement of Pasraman Yuana Bhuana Giri Tabanan has been equipped with some basic materials needed for the younger generation of Bali, including basic cultural material, leadership, nationalism, motivation to move forward, social pathology, health, and environmental care. Some people consider it important for the delivery of some materials for the post-conflict education, but there has been no specific evaluation of the impact of post-employment. To that end, the evaluative effort of the noble goal of pasraman is very necessary.
\end{abstract}

Keywords: Character education, next generation, pasraman

\begin{abstract}
Abstrak
Di antara gejala sosial destruktif mewarnai era globalisasi dewasa ini, adalah menguatnya faham Individualisme, merosotnya moralitas, dan budaya kosumerisme yang cenderung tidak menguntungkan bagi masa depan generasi penerus. Berbagai masalah ini bisa diantisipasi melalui penyelengaran pasraman. Makalah ini akan membahas (1) mengapa pasraman diperlukan dalam membangun karakter kepribadian generasi muda Bali? (2) bagaimana penyelenggaraan pasraman itu bisa efektif dalam membangun karakter kepribadian generasi muda Bali. Makalah ini merupakan hasil dari kajian evaluatif deskripstif yang datanya diperoleh dari studi dokumentasi dan wawancara dengan 12 informan peserta dan penyelengaraan Pasraman Yuana Bhuana Giri, di Perumnas Bukit Sanggulan, Tabanan. Hasil kajian membuktikan bahwa pertama, pasraman diperlukan untuk membentuk watak dan kepribadian generasi penerus yang memiliki budi pekerti (moralitas yang baik), tidak terjebak ke dalam budaya konsumerisme, memiliki etos kerja keras, dan memiliki motivasi untuk maju, siap bersaing dengan bangsa-bangsa maju lainnya. Kedua, penyelanggaraan Pasraman Yuana Bhuana Giri Tabanan selama ini sudah dilengkapi dengan beberapa materi dasar yang diperlukan untuk generasi muda Bali, termasuk materi budaya dasar, kepemimpinan,
\end{abstract}


nasionalisme, motivasi untuk maju, patologi sosial, kesehatan, dan peduli lingkungan. Beberapa kalangan memandang penting atas penyampaian beberapa materi untuk pendidikan pasraman tersebut, namun belum ada evalusi khusus tentang dampak penyelenggaraan pasraman. Untuk itu, upaya evaluative atas tujuan luhur penyelenggaraan pasraman amat diperlukan.

Kata kunci: Pendidikan karakter, generasi penerus, pasraman

\section{PENDAHULUAN}

Dewasa ini, kemajuan kehidupan manusia diwarnai oleh pesatnya perkembangan teknologi informasi dan komunikasi (TIK). Kehadiran teknologi informasi dan komunikasi (TIK) telah mengubah cara hidup masyarakat dunia dalam menjalankan aktivitas sehari-hari. Keberadaan dan peranan TIK di segala sektor kehidupan tanpa sadar telah membawa dunia memasuki era baru globalisasi lebih cepat dari yang dibayangkan semula. Hasilnya, informasi instant dapat diterima dan diikuti masyarakat di berbagai penjuru dunia. Perubahan-perubahan yang erjadi pada tingkat global mempengaruhi masyarakat-masyarakat tersebut (Azra, 2004). Dewasa ini pemanfaatan Internet telah mempengaruhi hampir seluruh aspek kehidupan manusia baik sosial, ekonomi, pendidikan, hiburan, dan bahkan keagamaan tanpa mengenal batas-batas geografis dan status sosial.

Kemajuan dalam penerapan Teknologi Informasi dan Komunikasi (TIK) secara umum memiliki dampakm baik dampak positif maupun dampak negatif. Diantara dampak negative yang menyertai kemajuan TIK adalah adanya gejala destruktif yang tidak menguntungjan generasi muda. Di antara gejala sosial destruktif mewarnai era globalisasi dewasa ini, adalah menguatnya faham Individualisme, merosotnya moralitas, serta budaya materialisme dan kosumerisme. Di kalangan genearsiu muda, efek negative kemajuan zaman sekarang ini antara lain diwarnai dengan meningkatkanya inetnsitas perilaku kriminalitas, kenakalan remaja, kasuus KTD sampai kasus narkoba dan HIV-AIDS. Diantata mereka juga terjebak ke dalam perilaku jalan pintas, ingin suskes dalam weaktu singkat, tanpa kerja keras. Meruyaknya kasus korupsi yang menyret semua kalangan, termasuk para petinggi di negeri ini sekarang adalah cermin nyata atas terjadinya erosi moralitas dan dominanya faham materialism dewasa ini.
Perilaku konsumtif sebagai indikasi materialism bisa terjadi juga akibat dari sistem pendidikan yang sedang berjalan. Sistem pendidkan di Indoinesia secara umum lebih bertujuan untuk mencetak mansuia yang pandai manghafak dan berhitung, bukan manusia yang penuh empati dengan sesamanya. Terjadi fenomena pengkelasan sosial dalam siatem pendidian dari TK sampai pergurian tinggi. Pendidikan telah diarahkan ke dalam sistem materialiem sehingga mencetak maunisia yang tidak memiliki solidaritas dengan sesamanya.

Selain itu, menurut Guru Besar Ilmu Manajemen Universitas Indonesia, Rhenald Kasali, sistem pendidikan di Indonesia kurang memperhatikan motorik. Ilmuwan-ilmuwan di Indonesia kurang membentuk konsep diri sehingga cenderung pintar namun sedikit bertindak. Rhenald mengingatkan bahwa manusia tidak hanya memiliki brain memory (otak) saja, melainkan juga myelin (memori otot). Sejauh ini, pendidikan di Indonesia terlalu mengedepankan pengetahuan dan hanya dibangun melalui jalur otak. Lebih jauh Rhenald mengungkapkan bahwa pengetahuan didapat dengan belajar, sedangkan keterampilan dari latihan. Selain itu, kelemahan sistem pendidikan di Indonesia adalah bidang studi dan materi yang terlalu luas. Sistem pendidikan Indonesia terlalu memaksa peserta didik untuk dapat menguasai sekian banyak bidang studi dengan materi yang sedemikian abstrak, yang selanjutnya membuat anak merasa tertekan/ stress yang dampaknya membuat mereka suka bolos, bosan sekolah, tawuran, mencontek, dan lain-lain. Alasan lain mengapa sistem pendidikan Indonesia perlu dibenahi adalah sistem pendidikan nasional sekarang, masih mengedepankan pada pencapaian berbasis nilai bukan pada keterampilan dan kompetensi sehingga kita tidak perlu bertanya dan bingung mengapa banyak sarjana yang menganggur, peserta olimpiade fisika yang tidak lulus Ujian 
Nasional dan banyak lagi hal-hal yang menggelikan dari sistem pendidikan ini.

Sistem pendidikan yang terlalu berorientasi pada nilai ternyata menghasilkan dua produk yaitu (1) pertama, pembunuhan kreatifitas berpikir dan berkarya serta hanya menciptakan pekerja. Kurikulum dalam sistem pendidikan Indonesia sangat membuat peserta didik menjadi pintar namun tidak menjadi cerdas. Sistem pendidikan nasional yang telah berlangsung hingga saat ini masih cenderung mengeksploitasi pemikiran peserta didik. (2) Produk kedua dari reaktan sistem pendidikan yang terlalu berorientasi pada nilai ialah pengesampingan aspek afektif (merasa) sehingga peserta didik hanya tercetak sebagai generasi-generasi yang pintar tapi tidak memiliki karakter-karakter yang dibutuhkan oleh bangsa ini. Sudah 65 tahun Indonesia merdeka dan setiap tahunnya keluar ribuan hingga jutaan kaum intelektual. Kenyataan pahitnya, hal tersebut tak kuasa mengubah nasib bangsa ini (on line 12 Juli 2014).

Pembenahan pendidikan untuk mewujudkan pribadi yang memiliki karakter kepribadian dan SDM berkualitas amat diperlukan. Menurut Megawangi (2003: 23) anak-anak akan tumbuh menjadi pribadi yang berkarakter jika ia tumbuh pada lingkungan yang berkarakter pula. Dengan begitu fitrah setiap anak yang dilahirkan suci bisa berkembang optimal. Oleh karenanya ada pihak yang mempunyai peran penting yaitu: keluarga, sekolah dan komunitas. Meskipun setiap anak dilahirkan dengan pembawaan yang baik namun dalam perkembangannya dia membutuhkan lingkungan yang baik pula untuk dapat menghasilkan karakter yang baik pula.

Kualitas sumber daya manusia menyangkut kemampuan manusia baik secara individu maupun bersama untuk bertahan hidup di tengah tuntutan kebutuhan dan ancaman persaingan. UU Sisdiknas Nomor 20 Tahun 2013 menguraikan bahwa Pendidikan adalah merupakan usaha sadar dan terencana untuk mewujudkan suasana belajar dan proses pembelajaran agar peserta didik secara aktif mengembangakan potensi dirinya untuk memiliki kekuatan spiritual keagamaan, pengendalian diri, kecerdasan, akhlak mulia, serta keterampilan yang diperlukan dirinya, masyarakat, bangsa dan Negara. Pendidikan memiliki fungsi dalam mengembangkan kemampuan dan membentuk watak serta peradaban bangsa yang bermartabat dalam rangka mencerdaskan kehidupan bangsa yang bertujuan untuk perkembangan potensi peserta didik agar menjadi manusia yang beriman dan bertaqwa kepada Tuhan Yang Maha Esa, Berakhlak mulia, sehat, berilmu, cakap, kreatif, mandiri, dan menjadi warga Negara yang demokratis serta bertanggung jawab.

Dalam meningkatkan muru pendidikan dalam agama Hindu PP. NO. 55 Pasal 38 Ayat 1 Tahun 2007 menerangkan bahwa pendidikan agama Hindu merupakan pendidikan berbasis masyarakat yang diselenggarakan dalam bentuk pasraman, Pesantian, dan bentuk lain yang sejenis. Pasraman sebagai lembaga pendidikan hindu memiliki peran penting dalam meningkatkan kualitas SDM hindu Bali. Makalah ini akan membahas: (1) mengapa pasraman diperlukan dalam membangun karakter kepribadian generasi muda Bali? (2) bagaimana penyelenggaraan pasraman itu bisa efektif dalam membangun karakter kepribadian generasi muda Bali. Makalah ini merupakan hasil dari kajian evaluatif deskriptif yang datanya diperoleh dari studi dokumentasi dan wawancara dengan 12 informan peserta dan penyelengaraan pasraman Yuana Bhuana Giri, di Perumnas Bukit Sanggulan, Tabanan.

\section{PEMBAHASAN}

\subsection{Mewujudkan Pendidikan Nasional Melalui Pasraman}

Pasraman merupakan konsep pendidikan Hindu di jaman dahulu yang tertuang di dalam kitab suci Veda. Sistem Asram menggambarkan hubungan yang akrab antara para guru dengan para sisyanya, bagaikan dalam sebuah keluarga, oleh karena itu sistem ini dikenal pula dengan nama sistem pendidikan "gurukula" (Tim Penyusun, 2006:11). Pada jaman dahulu pasraman (ashram) biasanya didirikan oleh seorang guru (acarya) di tempat yang sepi, jauh dari keramaian, dengan tujuan agar para sisya dapat belajar dengan khusuk dan sekaligus dekat dengan alam, seperti ashram para rsi. Tujuan pasraman adalah merupakan penjabaran/pelaksanaan dan pernyataan misi, seperti (1) Memberikan bekal kemampuan dasar kepada siswa untuk mengembangkan pribadi yang memiliki śraddhā dan bhakti 
kepada Tuhan Yang Maha Esa; (2) Membina siswa agar memiliki pengalaman, pengetahuan, dan ketrampilan yang dapat dikembangkan dalam kehidupannya (Tim Penyusun, 2006:16).

Sistem Pendidikan nasional diselenggarakan dalam rangka menyiapkan generasi penerus bangsa yang memiliki karakter mulia sehingga mampu mewujudkan cita-cita bangsa Indonesia yang tertuang dalam Pembukaan UndangUndang Dasar 1945, begitupula halnya pendidikan yang diselenggarakan di pasraman juga memiliki tujuan mulia yaitu menciptakan manusia yang memiliki karakter mulia sehingga mampu mengemban tugas sebagai warga negara dan tugas sebagai umat beragama, yang dikenal dengan istilah dharma negara dan dharma agama.

Secara luas pendidikan yang diselenggarakan harus mampu menjadikan anak didik memahami dan menguasai empat pilar pengetahuan, yaitu learning to do, learning to know, learning to live together, dan learning to be seperti yang dinyatakan oleh Jacques Delors (Delors, 1998:86). Melalui pendidikan yang berbasis pasraman seperti yang ada dalam ajaran Hindu diyakini akan mampu membuat anak didik memahami dan menguasai empat pilar pengetahuan tersebut, yakni: (1) learning to know yaitu anak didik mampu memahami ilmu apa yang seharusnya diketahui ketika mengikuti pendidikan di pasraman dan bagaimana cara memperoleh ilmu tersebut. Dalam ajaran Hindu anak-anak di pasraman dididik agar mereka mampu memahami apa yang disebut dengan Tri Kaya Parisudha dan Tat Twam Asi, serta bagaimana cara untuk mengetahuinya; (2) learning to do yaitu setelah anak didik mengetahui ilmu apa yang harus diketahui dan cara memperolehnya, dalam hal ini setelah memahami tri kaya parisudha dan tat twam asi sebagai pegangan hidup sebagai manusia yang harus berbagi dan bersosialisasi dengan semua mahluk hidup, selanjutnya anak didik diajarkan untuk mampu menerapkannya dalam kehidupan sehari-hari baik semasih di pasraman maupun setelah tamat dari pasraman; (3) learning to live together. Learning to live together akan dapat terwujud apabila anak didik diajarkan untuk terbiasa hidup bersama dalam waktu yang cukup lama dengan sesama anak didik di tempat yang sama, maka dengan memanfaatkan pasraman sebagai tempat anak didik menuntut ilmu dan bersosialisasi sangatlah tepat. Apabila anak didik terbiasa hidup dan bekerja sama yang dilandasi oleh ajaran tri kaya parisudha dan tat twam asi, maka setelah tamat dari pasraman anak didik akan mampu menjadi manusia yang supel, memiliki empati, solidaritas dan bertanggung jawab; dan (4) learning to be. Learning to be diyakini dapat dicapai apabila anak didik sudah mampu memahami dan mempraktekkan ketiga hal tersebut di atas, selanjutnya anak didik akan menjadi manusia seperti yang diharapkan yaitu menjadi manusia yang memiliki karakter yang mulia, manusia yang madhava penuh dengan kasih sayang, mampu berdiri sendiri serta bertanggung jawab, dengan demikian tidak akan ada anak-anak yang menentang guru di sekolah, orang tua dan tidak akan ada anak yang tawuran, dan saling membunuh sesama teman.

Pendidikan yang diselenggarakan di sekolah seperti saat ini kurang memberikan kesempatan kepada seorang guru untuk mendidik mental anak didik, karena keterbatasan waktu anak didik di sekolah, juga karena adanya campur tangan orang tua yang berlebihan, dan tanpa disadari hal itu menimbulkan dampak buruk pada diri anak sendiri, seperti anak memiliki sikap manja, mudah putus asa, kurang menghargai sesama dan kurang memiliki rasa hormat kepada guru.

Dengan menempatkan anak untuk tinggal di pasraman selama menjalankan pendidikannya, seorang guru akan memiliki kesempatan yang lebih banyak untuk mendidik karakter anak didiknya, sesuai dengan fungsi seorang guru yaitu selain mengajar juga memiliki tugas yang lebih mulia yaitu mendidik. Menurut kitab suci Veda seorang guru memiliki tugas dan tanggung jawab sebagai berikut: (1) 1. Tugas seorang guru adalah memberikan pengetahuan kepada orangorang yang bodoh (Rgveda I.6.3), (2) Seorang guru bagaikan sinar matahari menyebarkan terang (pengetahuan) (Rgveda VII.79.2), (3) Seorang pendidik pada waktu seorang siswa memberikan benang suci kepadanya dan berada di bawah pengawasannya (Atharvaveda XI. 5.3). (4) Kepala sekolah hendaknya keras bagaikan Yama, seorang hakim bagaikan dewa Varuna, pemberi semangat hidup bagaikan deva Soma yang menghancurkan sifat-sifat buruk bagaikan tumbuh-tumbuhan yang berkhasiat obat dan penyegar bagaikan air (Atharvaveda XI. 5.14) 
(Titib, 1996:429-435).

\subsection{Pasraman Sebagai Wahana Pendidikan Karakter}

Pendidikan karakter adalah pendekatan langsung untuk pendidikan moral yang melibatkan pengajaran moral dasar untuk para siswa agar mencegah mereka terlibat dalam perilaku tak bermoral dan melakukan hal yang berbahaya baik bagi diri mereka sendiri maupun orang lain (Santrock, 2009:138). Thomas Lickona berpendapat bahwa karakter merupakan kesatuan yang utuh antara pengetahuan moral, perasaan moral, dan perilaku moral, dimana ketiga hal tersebut saling berhubungan. Lebih lanjut Thomas Lickona mengatakan bahwa karakter yang baik terdiri dari mengetahui hal yang baik, menginginkan hal yang baik, dan melakukan hal yang baik (Lickona, 2012:82). Walaupun tidak persis sama dengan pernyataan Thomas Lickona, karakter masyarakat Bali pada umumnya juga dibangun melalui tiga hal, antara lain berpikir yang benar, berkata yang benar, dan berbuat yang benar. Ketiganya merupakan satu kesatuan yang utuh dan saling berhubungan. Apabila pikiran selalu diarahkan ke hal-hal yang benar maka ucapan yang keluarpun akan benar, dan selanjutnya wujud dari berpikir yang benar dan ucapan yang benar tersebut adalah adanya perilaku atau tindakan yang benar pula. Apabila seseorang dapat mewujudkan ketiga hal tersebut maka itulah yang disebut seseorang memiliki karakter yang baik.

Berkwits dalam tulisannya The Science of Character Education mendefinisikan Karakter sebagai berikut: "I define character as an individual's set of psychological characteristics that affect that person's ability and inclination to function morally. Simply put, character is comprised of those characteristics that lead a person to do the right thing or not do the right thing (Damon, 2002:69). Berdasarkan definisi Berkwits di atas dapat dikatakan bahwa karakter adalah merupakan suatu karakteristik psikologis individu yang mempengaruhi seseorang untuk melakukan hal yang benar atau tidak melakukan yang benar. Seorang bapak Pendidikan Nasional Ki Hajar Dewantara mengatakan bahwa karakter merupakan sebutan dalam bahasa asing, di Indonesia dinamakan budi pekerti atau watak. Budi pekerti atau watak atau karakter adalah bulatnya jiwa manusia, yaitu bersatunya gerak pikiran, perasaan, dan kehendak atau kemauan yang kemudian menimbulkan tenaga. Budi berarti "pikiran, perasaan, kemauan", sedangkan pekerti artinya "tenaga". Jadi budi pekerti adalah sifatnya jiwa manusia, mulai angan-angan hingga menjelma sebagai tenaga (Dewantara, 2004:25). Sedangkan menurut pengamatan seorang filsuf kontemporer bernama Michael Novak bahwa karakter merupakan campuran kompatibel dari seluruh kebaikan yang diidentifikasi oleh tradisi religius, cerita sastra, kaum bijaksana, dan kumpulan orang berakal sehat yang ada dalam sejarah (Lickona, 2012:81). Karakter menurut Ryan dan Bohlin, mengandung tiga unsur pokok yaitu mengetahui kebaikan (knowing the good), mencintai kebaikan (loving the good), dan melakukan kebaikan (doing the good) (online, 25 Desember 2012). Ryan dan Bohlin mengatakan "keutamaan atau kebaikan itu tumbuh dari dalam diri individu dan secara aktual mengembangkan karakter dan inteligensinya" (Koesoema, 2012:177).

Sri Swami Sivananda mengatakan "kecendrungan batin yang membuat kehendak menjadi mungkin disebut watak atau karakter" (Sivananda, 2003:64). Lebih lanjut Swami Sivananda mengatakan bahwa pemikiranlah yang membentuk karakter, sehingga apabila seseorang menunjukkan pemikiran mulia maka seseorang akan megembangkan karakter mulia pula, namun apabila seseorang menunjukkan pemikiran jahat maka seseorang akan mengembangkan karakter yang nista atau buruk (Sivananda, 2003:79). Mahatma Gandhi mengatakan bahwa ada tujuh kejahatan atau dosa yang dilakukan oleh manusia modern sekarang ini, dimana ketujuh kejahatan itu merupakan penerapan tingkah laku yang salah yang dilakukan bahkan oleh setiap manusia yang tidak mengenal etika kehidupan yang baik. Dari ketujuh kejahatan itu salah satunya adalah "pengetahuan tanpa karakter" (Atmaja, 2010:7).

Satu periode pasraman dilaksanakan dselama 15 hari, setiap hari minggu. Pelaksanaanya dilangsungkan di wantilan, tanpa meja belalajar banjar perumahan Sanggulan setempat. Beberapa materi yang relevan dibahas dan dijadikan bekal bagi peserta pasraman adalah materi dasar atau materi pokok dan materi penunjang. Beberapa materi dasar untuk 
pendidikan pasraman meliputi: Agama, Budi pekerti, Ilmu budaya dasar (tentang tradisi budaya Bali), Kepemimpinan, dan Kebangsaan. Selanjutnya materi penunjang, meliputi: patologi sosial, tantangan globalisasi, kompetensi khususu dalam persaingan di masa depan. Penyampaian beberepa materi pelatihan ini memiliki tujuan. Secara umum, penyampaian materi pokok bertujuan agar peserta didik memiliki kesadaran moralitas yang tinggi, berbudaya, memiliki jiwa kepemimpinan dan cinta tanah air. Selanjutnya materi penunjang disampaikan agar peserta didik memahami patologi sosial (termasuk kriminalitas, HIVAIDS, narkoba), dan tangan globalisasi, serta skill/kompetensi yang diperlukan untuk memenangkan persaingan global (lihat Tabel 1).

Tabel 2.1

Materi pelatihan/Pasaraman dan kegunaannya

\begin{tabular}{|c|c|}
\hline Materi Pelatihan & Kegunaan/Tujuan \\
\hline $\begin{array}{ll}\text { Materi dasar: } \\
\text { - } & \text { Agama } \\
\text { - } & \text { Budi pekerti } \\
\text { - } & \text { Ilmu budaya dasar } \\
& \text { (tradisi budaya Bali), } \\
& \text { Kepemimpinan } \\
\text { - } & \text { Kebangsaan. }\end{array}$ & $\begin{array}{l}\text { Peserta didik memiliki } \\
\text { kesadaran moralitas } \\
\text { yang tinggi, berbudaya, } \\
\text { memiliki jiwa } \\
\text { kepemimpinan dan cinta } \\
\text { tanah air }\end{array}$ \\
\hline $\begin{array}{ll}\text { Materi penunjang: } \\
\text { - } & \text { Patologi sosial } \\
\text { - } & \text { Tantangan globalisasi } \\
\text { - } & \text { Skill/kompetensi } \\
& \text { khususu dalam } \\
\text { persaingan di masa } \\
\text { depan }\end{array}$ & $\begin{array}{l}\text { Peserta didik memahami } \\
\text { patologi sosial (termasuk } \\
\text { kriminalitas, HIV-AIDS, } \\
\text { narkoba), dan tangan } \\
\text { globalisasi, serta skill/ } \\
\text { kompetensi yang } \\
\text { diperlukan untuk } \\
\text { memenangkan } \\
\text { persaingan global. }\end{array}$ \\
\hline
\end{tabular}

Mempertimbangkan paket materi yang dibahas dalam pasraman remaja desa tersebut, semua informan menilai positif bahwa materi sudah cukup konstruktif untuk mencetak generasi muda Bali yang berkarakter. Materi pasraman tersebut sudah mengenai sasaran sesuai dengan tujuan pasraman, tetapi sebagian materi pasraman masih belum disampaikan secara intensif. Materi yang terkait dengan budi pekerti, agama dan tradisi sudah cukup intensif. Pasraman yang diikuti oleh remaja usia serkolah dasar kelas IV, V dan VI tersebut telah mengajarkan keterampilan terkait dengan penyiapaian sarana upakara agama Hindu, termasuk belajar mengania mejejahitan dan pembuatan alat upacara lainnya (lihat Gambar 1 dan 2).Sementara materi penunjang, termasuk materi terkait masalah sosial (patologi sosial) belum dibahas secara intens. Nampaknya penyelenggara perlu bekerjadsma dengan pihak BNN dan KPA Kabupaten setempat untuk membahads masalah HIV-AIDS dan narkoba ini.

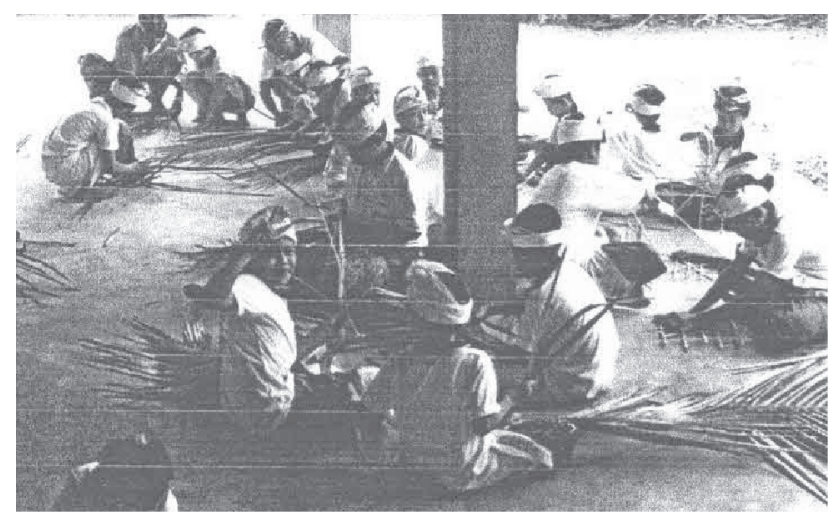

Gambar 1

Peseta pasraman putra: membuat alat upakara Sumber: Murjana, 2013 (repro)

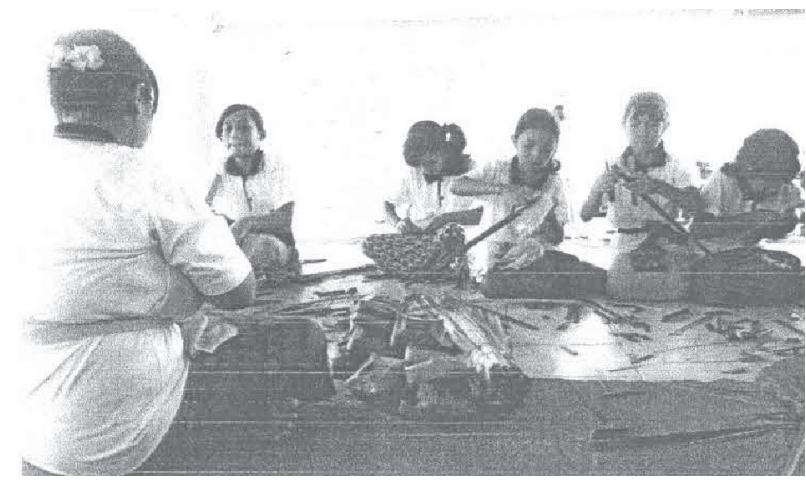

Gambar 2

Peseta pasraman putri: berlatih mejejahitan Sumber: Murjana, 2013 (repro)

Sejauh ini belum ada evaluasi dampak pasraman terhadap kepribadian remaja peserta pasraman sehingga belum diketahui secara pasti tentang manfaat penyelenggaraan pasraman. Untuk mengetahui keberhasilan proses pasraman semestinya disiapkan modul yang terstandar (terakreditasi) sehinga penyelenggaraan pasraman benar-benar bisa diakui kualitasnya. Selain itu, pre dan post test diperlukan untuk mengetahui kemanfaatan dari penyelenggaraan pasraman. 


\section{PENUTUP}

Pasraman diperlukan untuk membentuk watak dan kepribadian generasi penerus yang memiliki budi pekerti (moralitas yang baik), tidak terjebak ke dalam budaya konsumerisme, memiliki etos kerja keras, dan memiliki motivasi untuk maju, siap bersaing dengan bangsabangsa maju lainnya. Penyelanggaraan pasraman Yuana Bhuana Giri, di Perumnas Bukit Sanggulan, Tabanan selama ini sudah dilengkapi dengan beberapa materi dasar yang diperlukan untuk generasi muda Bali, termasuk materi budaya dasar, kepemimpinan, nasionalisme, motivasi untuk maju, patologi sosial, kesehatan, dan peduli lingkungan. Beberapa kalangan memandang penting atas penyampaian beberapa materi untuk pendidikan pasraman tersebut, namun belum ada evalusi khusus tentang dampak penyelenggaraan pasraman.

Untuk melengkapi materi inti, yakni budi pekerja dan agama Hindu, pemberian materi patologi sosial (HIV-AIDS dan narkoba) perlu diberikan kepada genearasu muda Hindu peserta pasraman, agar mereka mampu menghindari masalah patologi sosial di era globalisasi saat ini.

\section{DAFTAR PUSTAKA}

Azra, Azyumardi. 2004. "Pergeseran Paradigma Pembelajaran dalam Menghadapi Persaingan Global". Makalah Seminar Nasional Teknologi Pembelajaran Menghadapi Tantangan Daya Saing SDM Nasional dan Internasional. Di Aiditorium Depdiknas, 1-2 Desember 2004.

Atmaja, I Made Nada, dkk. 2010. Etika Hindu. Surabaya: Paramita.

Damon, William. 2002. Bringing in A New Era in Character Education. Californea: Hoover institution Press.

Delors, Jacques. 1998. Learning: The Treasure Within. Paris: UNESCO.

Dewantara, K.H. 2004. Pendidikan. Yogyakarta: Majelis Luhur Persatuan Taman Siswa.

Koesoema, Doni. 2012. Pendidikan Karakter utuh dan Menyeluruh. Yogyakarta: Kanisius.

Lickona, Thomas. 2012. Educating for Character Ed 1 (terjemahan Juma Abdu Wamaungo). Jakarta: Bumi Aksara.

Megawangi, Ratna. 2003. Pendidikan Karakter untuk Membangun Masyarakat Madani. IPPK Indonesia Heritage Foundation.

Murjana, I Nengah. 2013. Pola Pembelajaran Agama Hindu sebagai pendidikan non formal di Pasraman Yuana Bhuana Giri, di Perumnas Bukit Sanggulan, Tabanan

Santrock, John W. 2009. Psikologi Pendidikan terjemahan Diana Angelica. Jakarta: salemba Humanika. Sivananda, Sri Swami. 2003. Inti Sari Ajaran Agama Hindu. Surabaya: Paramita.

Tim Penyusun. 2006. Pedoman Pengelolaan Pasraman. Surabaya: Paramita.

Titib, I Made. 2007. Studi Agama Hindu: Masalah dan Solusi

Undang-Undang Nomor 20 Tahun 2003 tentang Sistem Pendidikan Nasional

PP. NO. 55 Tahun 2007 Tentang Pendidikan Agama dan Pendidikan Keagamaan 